ojs.uv.es/index.php/qdfed

Rebut: 3I.05.202I. Acceptat: 28.09.2021

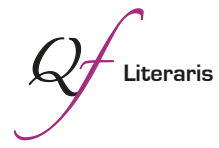

Per a citar aquest article: Míguez Macho, Antonio. 202I. "El perpetrador en su laberinto. Un análisis comparado de cómo los perpetradores habitan los espacios de memoria". Quaderns de Filologia: Estudis Literaris XXVI: I63-I80.

doi: $10.7203 /$ qdfed.26.22106

\title{
El perpetrador en su laberinto. Un análisis comparado de cómo los perpetradores habitan los espacios de memoria
}

\author{
The perpetrator in its own labyrinth. A comparative analysis of how \\ perpetrators inhabit the sites of memory
}

\author{
Antonio Míguez Macho \\ Universidade de Santiago de Compostela \\ antonio.miguez@usc.es
}

Resumen: El estudio de los lugares de memoria de la violencia masiva está ligado a las prácticas de violencia y, en el plano de la memoria, a la gestión del recuerdo de las víctimas. Sin embargo, sabemos que la violencia se constituye como una acción compartida en la que, junto a la víctima o víctimas, se halla (visible u oculta, como con frecuencia acontece) la figura del verdugo o de los verdugos. A partir de un estudio comparado del rol de los que no son víctimas en la construcción de la memoria colectiva de los pasados traumáticos, de Choeung Ek a Buenos Aires, y de Madrid a Kiev, se presenta una propuesta de análisis que discute la complejidad de la presencia de lo ausente en términos de los regímenes de memoria de nuestro tiempo. En un viaje a través de los espacios, los memoriales y los lugares de negación y amnesia, observaremos el modo en que la figura de los perpetradores se representa o se oculta en su propio laberinto.

Palabras clave: lugares de memoria; violencia masiva; memoria colectiva; perpetradores; negación.

\begin{abstract}
The study of the sites of memory of mass violence is related to the practices of violence and, at the level of memory, to the management of the memory of the victims. However, we know that violence is constituted as a shared action in which together with the victim or victims, there is (visible or hidden, as often happens) the figure of the executioner or executioners. Based on a comparative analysis of the role of those who are not victims in the construction of the collective memory of traumatic pasts, from Choeung Ek to Buenos Aires, and from Madrid to Kiev, an analysis proposal is presented that discusses the complexity of the presence of the absent in terms of the memory regimes of our time. In a trip through spaces, memorials and places of denial and amnesia, we would observe the way in which the figure of the perpetrator is represented or hidden in its own labyrinth.
\end{abstract}

Keywords: sites of memory; mass violence; collective memory; perpetrators; denial. 


\section{La memoria de lo otro}

Este texto indaga en el rol de los que no son víctimas en la construcción de la memoria colectiva de los pasados traumáticos. En esta idea inicial se contienen al menos tres nociones fundamentales que conviene aclarar en primera instancia. Comenzando por el tiempo histórico, los pasados traumáticos (I) abarcan los fenómenos de violencia que son incorporados, frecuentemente en sucesivas capas, al patrimonio de la memoria colectiva de una sociedad a modo de experiencia (Koselleck, I993: 338). El proceso de "incorporación" de los pasados traumáticos a los sucesivos presentes se realiza a través de fórmulas de transmisión diversas que transitan desde la memorialización hasta la negación y el olvido. Son procesos sociales, por tanto ni automáticos, ni lineales, ni por principio consensuales. La idea de memoria colectiva como un proceso construido socialmente (2) remite a esta condición conflictiva y radicalmente histórica de sus contextos de elaboración. En ella participan, tal y como el propio Halbwachs tuvo la intuición de entender, diferentes sujetos sociales o instituciones que no habitan en el pasado, sino en el presente: "el pensamiento social es básicamente una memoria, y todo su contenido está hecho de recuerdos colectivos, pero solo permanecen presentes en la sociedad esos recuerdos que la sociedad, trabajando sobre sus marcos actuales, puede reconstruir" (Halbwachs, 2004: 344). Existen además una pluralidad de roles (3) que se ubican en el marco de la memoria colectiva de los pasados traumáticos. En el tiempo histórico, los procesos de violencia que son objeto de nuestra atención se definen por la presencia de perpetradores y víctimas: sin la figura de unos y de otros no existirían. La propia noción de quién ocupa cada uno de esos papeles es en sí mismo objeto de elaboración por la memoria colectiva. Sin embargo, cabe subrayar que ambos perfiles no son más que extremos en una amplia gama de intermediarios que en última instancia son parte constitutiva del mismo pasado traumático al que hacemos referencia. $\mathrm{Su}$ existencia en la memoria colectiva se relaciona con la propia noción de "culpabilidad" y las sucesivas estrategias elusivas para abordarla (Olick, 2007: 49).

Aunque existe una enorme complejidad en los procesos que analizamos, es posible identificar tres elementos basales en todos ellos. Uno refiere al papel absolutamente central de la víctima en el proceso de construcción de la memoria colectiva de los pasados traumáticos de nuestro tiempo. En segundo lugar, conviene destacar la globalización de la memoria como un acontecimiento histórico del mundo contemporáneo. Ambos fenómenos tienen raí- 
ces que se pueden rastrear en los diversos regímenes de memoria del pasado y del presente. Finalmente, existe un tercer elemento algo menos explorado y sobre el que precisamente se centrará este texto: la falta de representación de la figura de los que no son víctimas en la materialización de la memoria que constituyen los lugares. Para ello, mostraremos a través de diversos ejemplos históricos el modo en que se ha abordado la representación de la memoria colectiva en el espacio, prestando especial atención a la presencia o ausencia de los perpetradores en su seno.

\section{Un campamento indio y la danza de los espíritus}

La historia es conocida. En los últimos días de I89o, el Séptimo de Caballería del Ejército de Estados Unidos fue enviado al campamento de los indios Lakota en la reserva de Pine Ridge, en Dakota del Sur. Las instrucciones de los militares eran confinar a los nativos, desarmarlos y acabar con la práctica de la danza de los espíritus, que se consideraba potencialmente insurreccional y una amenaza para la seguridad de Estados Unidos (Andersson, 2008: I43I6I). El 29 de diciembre, con los soldados ya en el campamento, un confuso incidente que involucró a un nativo sordo, Coyote Negro, que supuestamente no entendió las órdenes de entregar su rifle a los soldados, y el repentino comienzo de la danza de los espíritus por otros miembros de la tribu, sirvió de preludio a la masacre. El gran jefe Pie Grande y algo más de doscientos lakota, hombres, mujeres y niños, fueron asesinados en el acto (dependiendo de las fuentes, la cifra alcanza los trescientos). A continuación, los cadáveres de los nativos fueron enterrados en una fosa común en una colina cercana. En cuanto a los soldados, tuvieron sobre una veintena de bajas y algunos heridos (Utley, 2004: 200-230).

Esta matanza forma parte de una larga serie de enfrentamientos conocidos como Indian wars, en este caso, cuando estas llegaban a su fin. Diversos casos anteriores de masacres o acontecimientos señalados como el "Sendero de Lágrimas" marcan una historia de exterminio y segregación de la población nativa americana en el continente. De las distintas exclusiones con las que la historia constitucional del liberalismo ha ido conformándose desde sus orígenes, incluido el proceso de independencia norteamericano, la única a la que probablemente no ha sido factible dar respuesta en lenguaje de derechos es la de los pueblos originarios. Este hecho se refleja de manera extrema en la memorialización de este pasado traumático, en el lugar de los verdugos y las 
víctimas y en los intermediarios. En el caso concreto que nos ocupa, veinte integrantes del Séptimo de Caballería fueron condecorados con la Medalla de Honor del Congreso por su valor en lo que pasó a denominarse "batalla de Wounded Knee". En I893, un monumento en honor a los soldados caídos en la acción fue erigido en Fort Riley, Kansas, un lugar de formación de la escuela de caballería del ejército que continúa siendo una instalación militar a día de hoy. El monumento forma parte de las atracciones históricas del patrimonio de Fort Riley, presentado como un testimonio válido de un pasado de violencia mutua:

El séptimo de caballería y la batería de la primera artillería, comandada por el coronel James Forsyth, abandonaron Fort Riley en diciembre de I89o durante la campaña del ejército para pacificar a una banda de indios sioux. Cuando los soldados llegaron al campamento de Big Foot cerca de Wounded Knee Creek, Dakota del Sur, los indios izaron una bandera de tregua. Los soldados estaban recogiendo las armas de los indios cuando alguien empezó a disparar. No está claro cómo ni por qué comenzó la batalla. Algunos dicen que un indio llamado Black Fox sacó una escopeta de debajo de una manta. Algunos dicen que el Séptimo de Caballería quería venganza por la derrota de Little Big Horn. Cuando los disparos terminaron, 29 soldados de caballería murieron, junto con 300 hombres, mujeres y niños. Forsyth fue relevado del mando pero restablecido tras una investigación. Esta batalla resultaría ser la última acción significativa del Ejército de EEUU contra el Sioux (U.S. Army, 2020: I2).

Si observamos el monumento de los soldados caídos, constituye un ejemplo de piedra erigida que nos es familiar porque lo hemos visto mil veces repetido en los monumentos a los caídos que se extienden por Europa después de la Primera Guerra Mundial. Lo cierto es que son los norteamericanos los que anticipan estas prácticas al hilo de la Guerra de Secesión, momento en el que también se "inventa" el concepto de cementerio militar (Laqueur, I996: I53). No existe una noción de diferencia entre víctima y verdugo en la lógica aplicada en estas prácticas: simplemente se considera a los militares caídos (a los que se enumera sin aparente distinción con las otras víctimas) como sujetos que deben ser glorificados y cuyo esfuerzo al dar su vida por la patria ha de ser justificado, sea lo que sea que hayan hecho.

Las lógicas seguidas por el ejército de Estados Unidos a la hora de memorializar a sus caídos fueron imitadas por sus propias víctimas, los indios lakota. Estos, a finales de la década de I89o, comienzan los trámites para ser autorizados a erigir un monumento a sus víctimas, inspirándose en los obeliscos a los caídos dedicados a los soldados del ejército de los Estados Uni- 
dos. Ya en i886, el gran jefe Toro Sentado había visitado el campo de batalla de Bighorn, en Montana, donde se ubica el cementerio nacional de Custer y el obelisco erigido en I88I al propio Custer y al Séptimo de Caballería. El obelisco de Last Stand Hill fue reinterpretado por el gran jefe indio como un monumento dedicado a sus guerreros, antes que a lo heroico del accionar de Custer. El aprendizaje del significado de estos monumentos y su traslación a una cultura distinta es muestra del fenómeno incipiente de globalización de la memoria que ya hemos mencionado. El acto en sí de inauguración del monumento tuvo lugar en I903, auspiciado por la colaboración de una Iglesia episcopaliana situada en las inmediaciones (Grua, 2015: 35). En el texto de la inscripción del monumento, en idioma lakota, se indican los nombres de los asesinados en Wounded Knee y se dice:

Este monumento fue erigido por familiares sobrevivientes y otros indios sioux de los ríos Ogalala y Cheyenne en memoria de la masacre del jefe Big Foot el 29 de diciembre de I890. El coronel Forsyth al mando de las tropas estadounidenses. Big Foot fue un gran jefe de los indios sioux. A menudo decía: "Estaré en paz hasta que llegue mi último día". Realizó muchas acciones buenas y valientes por el hombre blanco y el piel roja. Muchas mujeres y niños inocentes de los que no se sabe que hicieran nada malo murieron aquí (Utley, 2004: 5).

A pesar de la contraposición de ambos monumentos, fueron incorporados al patrimonio histórico de los Estados Unidos. En ellos conviene subrayar algo que, como veremos a continuación, se va disipando en la historia del siglo xx: tanto uno como otro, junto a las víctimas que recuerdan, señalan con nombres y apellidos al perpetrador. A nivel histórico, la presencia del contexto y nombres de los autores materiales de la matanza es en sí misma un elemento de memorialización.

\section{Blancos, rojos y la reconciliación}

La enorme cantidad de víctimas que causó la Primera Guerra Mundial provocó la necesidad de que los gobiernos desarrollasen una nueva política de memorialización asociada a la omnipresente figura de los "caídos". Los cenotafios (sepulcros vacíos), los obeliscos y las tumbas al soldado desconocido se reprodujeron en cada una de las ciudades y pueblos de Europa de entreguerras y de ahí se imitaron en el resto del mundo (Mosse, I990: I7-I9). Esta política de la memoria estuvo asociada directamente a desarrollar una narrativa de "justificación" nacional motivada por los resultados de las políticas de 
reclutamiento masivo. Si la guerra total multiplicaba las víctimas como nunca antes se había visto, las políticas de memorialización se volvieron también inmensas. Sin embargo, en el mismo periodo surgieron múltiples conflictos, en la propia guerra o por consecuencia más o menos directa de la guerra. En ellos, la política de justificación de los caídos con una dimensión nacional se enfrentaba a unos desafíos distintos: esto sucedía, por ejemplo, en las guerras civiles. Uno de los casos paradigmáticos en términos de gestión de la memoria fue la guerra civil en Finlandia, que enfrentó en I9I8 a los "blancos" (conservadores y nacionalistas) con los "rojos" (revolucionarios e internacionalistas). A pesar de la brevedad de la guerra, el balance de víctimas no combatientes fue mucho más elevado que el de los propios soldados (Tikka, 20I4: 90-II8). Cada conquista de un territorio que se encontraba en manos enemigas, se acompañó de una política de asesinato contra los habitantes del territorio conquistado, independientemente de su condición de combatientes o no. Los datos indican que fueron asesinados 27.500 rojos, por algo menos de 5.000 blancos, restando unos 2.000 que no se pueden atribuir con claridad a uno $u$ otro bando. Hablamos de un total de 34.200 víctimas, pero muy desigualmente repartidas. Fueron asesinados seis veces más rojos que blancos (Suomen Sotasurmat I9I4-I922, 2004). En todo caso, casi un I \% de la población de Finlandia fue víctima de esta guerra de meses, un porcentaje semejante al de la guerra civil norteamericana en cuatro años.

La interpretación de la guerra de los vencedores, los "blancos", se convirtió en la gran verdad nacional, la que se enseñaba en las escuelas, de la que el ejército, la Iglesia y el sistema legal eran los depositarios. Por otro lado, la "narrativa obrera", la de los perdedores, que hablaba de ejecuciones arbitrarias y represalias de los vencedores (pérdida de derechos civiles), constituyó la pequeña tradición, que quedó en el ámbito familiar y en la tradición oral. Como muestra monumental de toda esta memoria de exclusión se erigió el "memorial de las víctimas" inaugurado en I920 en Helsinki, en el que los únicos caídos que se conmemoraban eran "los blancos". Fueron cientos los monumentos más construidos para honrar a las únicas "víctimas" consideradas honorables en aquel momento (Szpunar, 20I2: I2I6).

Esta situación cambió con el significado de unidad nacional que el nacionalismo finlandés otorga a la guerra contra los soviéticos (I939-I940) (Peltonen, 2002: I92-I93). Simbólicamente, en I970 se inauguró un nuevo monumento dedicado a la memoria de las "víctimas rojas" de la guerra civil. Supone la culminación de un proceso de reincorporación de la memoria de los rojos a la memoria nacional de Finlandia (Upton, I98I: 447-48I). Los dos monumentos 
conviven en Helsinki y visualizan la memoria del consenso. En I998, el gobierno de Finlandia financió el proyecto "víctimas de la guerra en Finlandia", llevado a cabo desde Archivos Nacionales con el objetivo de identificar las casi 40.000 víctimas de conflictos entre el inicio de la Primera Guerra Mundial y el final de la intervención finlandesa en la guerra civil rusa. A pesar de que la mayoría de las víctimas identificadas, 35.000-37.000 pertenecía a la guerra civil, el proyecto evitó llamarse "víctimas de la guerra civil", para no reabrir viejas heridas. Al tiempo, ninguna política concreta se adoptó para nombrar, buscar y aun identificar a los perpetradores. Al admitirse la existencia de víctimas por ambos bandos, la figura del verdugo se difuminaba en su seno.

En el propio periodo de entreguerras tuvo lugar la guerra civil española, que ya establece una continuidad entre esta época y la Segunda Guerra Mundial. El golpe de Estado de I936, la violencia golpista y la dictadura franquista legaron una multiplicidad de espacios de memoria del pasado traumático en España en los cuales se ha intervenido de manera muy intensa hasta el día de hoy. En el caso del Valle de los Caídos, se trata de un proyecto constructivo iniciado en la inmediata posguerra (I940) y que seguía de manera fiel la lógica de memorialización del culto a los "caídos" convertida en paradigma tras la Primera Guerra Mundial. Tal y como sucedió en Finlandia, existía una selección de los muertos que se honraban de modo excluyente, pues el monumento solo pretendía honrar a los combatientes del llamado "bando nacional”. Tal y como proclamaba su decreto de construcción, el complejo memorial de estética netamente fascista, se construía porque "es necesario que las piedras que se levanten tengan la grandeza de los monumentos antiguos, que desafíen al tiempo y al olvido y que constituyan lugar de meditación y de reposo en que las generaciones futuras rindan tributo de admiración a los que les legaron una España mejor" (BOE, I940: 2240). El Douaumont o Hohenstein de Franco, sin embargo, fue reconvertido simbólicamente en la fase final próxima a su inauguración (I959) y en las décadas posteriores en un monumento dedicado a los "caídos por los dos bandos". Esto llevó a una política de exhumaciones de soldados republicanos aun contra el criterio de sus familias, con el fin de trasladar sus restos al osario (Ferrándiz, 20I4: 26I-304). Con el traslado masivo de restos de fallecidos en la Guerra Civil, el monumento pasó a ser la mayor fosa común de España con más de 33.000 cuerpos enterrados, presidido por las figuras de José Antonio Primo de Rivera y el propio Franco. Es tan poderoso el argumento de los "caídos", que aún en agosto de 2018 cuando el gobierno aprobó un Real Decreto en el que establece la exhumación del dictador por la vía de modificar la "Ley de Memoria Histórica" de 2007, 
esgrimió como argumento que allí "sólo podrán yacer los restos mortales de personas fallecidas a consecuencia de la Guerra Civil española, como lugar de conmemoración, recuerdo y homenaje a las víctimas de la contienda" (BOE, 2018: 84607-84610). Dicho de otra manera, la expulsión de Franco no se produce porque este sea un perpetrador, el verdugo por excelencia de la masacre española, sino porque no alcanza el rango de víctima.

La política de reconversión de los monumentos de caídos en el caso español como espacios de reconciliación se intentó también con otros lugares de especial significado simbólico, como puede ser el caso del monumento en el Castillo de Montjuïc a los fusilados durante la guerra en Barcelona. Este monumento había sido construido por el franquismo triunfante (Baldrich, Ros i de Ramis, Soteras y Solà-Morales, Miquel y Llucià Oslé, I940) para apropiarse de la memoria de aquellas víctimas y pasar a integrarlas en su particular corpus de "caídos". Los esfuerzos por resignificar el monumento en tiempos de democracia han sido ímprobos y ciertamente curiosos. Por una parte, se modificaron en I986 las palabras que estaban inscritas en el arco: "Caídos por Dios y por España, ¡Presentes!”, siendo sustituidas por otra inscripción que decía: "Honor a todos los que dieron su vida por España". Posteriormente, también se retiró del monumento un águila franquista hecha en bronce y se realizó una nueva inscripción que decía: "En memoria de cuantos fueron fusilados en este Foso de Santa Elena y de todas las víctimas de la Guerra Civil" (Fabre, Huertas y Ainaud, 20I6). A pesar de todas estas modificaciones, el lugar solo albergaba una ceremonia anual de los nostálgicos del franquismo, que se siguió celebrando hasta que en 2015 fue prohibida por orden de la alcaldía de Barcelona.

Si el Valle de los Caídos o el monumento a los caídos de Montjuïc siguen en pie, sin saber muy bien qué hacer con ellos y con su significado, la mayor parte de la simbología franquista ha sido retirada del espacio público. Los cambios en los nombres de calles, las retiradas de monumentos, han ido en paralelo a la proliferación de múltiples memoriales dedicados a las "víctimas del franquismo", en un proceso que se ha iniciado en los años de la Transición española y que continúa en la actualidad. De un modo poco o nada frecuente en el plano internacional, este tipo de medidas han sido codificadas bajo una ley, la llamada "Ley de Memoria Histórica” (2007) (BOE, 2007: 534IO y 534II). Ello no ha significado, sin embargo, que ninguna de estas medidas estuviera dirigida en particular a identificar, señalar ni mucho menos representar en los espacios memoriales a los verdugos: fueron acciones consagradas a subsanar lo que se consideraba un olvido injustificable de la memoria de las víctimas 
(Míguez, 20I4: I93-I96). Tal y como señalaba un estudio del CIS de 2005 que preguntaba sobre los temas de "memoria histórica", el único consenso amplio existente entre los ciudadanos españoles (más de un $70 \%$ de acuerdo) se refería a la necesidad de propugnar medidas que permitiesen homenajear por igual a las "víctimas de los dos bandos" (CIS, 2005).

\section{El fantasma de un velódromo en París y unos azulejos en Budapest}

En los casos de Finlandia o España representar a los verdugos en sus propios espacios de violencia significaba poner en duda la memoria de la reconciliación, sucedáneo de un pretendido consenso que se revelaba una quimera o un discurso mítico de justificación nacional. Sin embargo, estas memorias locales no se sitúan al margen de los contextos globales, en los que la memoria del "Holocausto" ha significado un patrón de conmemoración no solo de la víctima por antonomasia, sino también del verdugo como ente absoluto. Este verdugo se ha presentado siempre como "el otro". Un ejemplo de ello es lo sucedido con la memoria de la redada del Velódromo de Invierno de París, de i942. Fue la mayor operación realizada contra los judíos acontecida en Francia, cuyo accionar se organizó y ejecutó por las autoridades y fuerzas de seguridad francesas. Vel d'Hiv constituye un símbolo de la suerte que vivieron los judíos en el país durante el periodo (Wieviorka, I999: I62). En el lugar donde se concentró a una parte de los detenidos, el propio velódromo, fue colocada en I946 una sencilla placa por un grupo de ciudadanos. Su sobriedad es evidente, como también la voluntad inequívoca de denuncia. El texto, muy conciso e informativo, señalaba: "entre los días I6 y i7 de julio de I942, I3.152 judíos fueron arrestados en París y sus alrededores, deportados a Auschwitz y asesinados por orden de los ocupantes nazis. La policía del gobierno de Vichy encerró en condiciones inhumanas a I.I29 hombres, 2.9I6 mujeres y 4.II5 niños en el Vélodrome d'Hiver, que se alzaba en este lugar. Nuestro agradecimiento para aquellos que intentaron salvarles. Caminante que pasas por aquí, ¡recuerda!". El velódromo fue derribado en la década de I950, pero subsistió la placa, como testimonio de un consenso por el cual el mal de Francia lo habían causado otros, aquellos que se mencionan: los ocupantes nazis y la policía del gobierno de Vichy. Sin embargo, el hecho de toparse con el verdugo provocó una conmoción en esta retórica consensual. Los procesos judiciales de I987 contra el llamado "carnicero de Lyon", Klaus Barbie, el jefe de la policía de Vichy, René Bousquet, y el líder de la milicia de Lyon, Paul Touvier, no dejaban 
lugar a dudas sobre la extensa colaboración de los propios franceses con el proceso de deportación. Ni el propio mito de "el vencedor de Verdún", el mariscal Pétain, pudo sobrevivir a ello (Rousso, 2006: 333). En I994, se inauguró un segundo monumento a pocos metros de la modesta placa (Walter Spitzer y Mario Azagury, "N’oublions jamais"). Se trataba de una expresión artística mucho más visible y con un texto mucho menos descriptivo: "La República Francesa en homenaje a las víctimas de las persecuciones racistas y antisemitas y los crímenes contra la humanidad cometidos bajo la autoridad del gobierno de facto del Estado Francés" (Musée de la Résistance, 20I3). El final es también diferente: ya no se dice "recuerda", de modo imperativo, sino un "no olvidaremos nunca". A pesar de que el mito de la Francia resistente había sufrido un golpe mortal en aquellos momentos, la figura del perpetrador en el monumento, el colaboracionista si se quiere, quedó reducido a una escueta mención al "gobierno de facto del Estado Francés". El propio Chirac hubo de realizar en 1995 frente al monumento un acto de contrición en el que se asumía la responsabilidad de Francia en los hechos, algo que repitió Hollande en 2012 y Macron en 20I7. Son palabras que sustituyen las carencias del espacio monumental.

De este modo, ya inmersos en plena época de la memoria a partir de la década de I990, abundan las expresiones memoriales que inciden en la centralidad de la víctima y en el papel de la conmemoración como elemento aglutinador de los nuevos consensos nacionales. Por ejemplo, esto ha sucedido en la Europa poscomunista. En la ciudad de Budapest, se erige el conocido como "monumento de los zapatos", dedicado a la memoria de los veinte mil judíos que habían sido ejecutados entre finales del año i944 y comienzos del I945 en las orillas del Danubio por miembros del Partido de la Cruz Flechada. El monumento en sí mismo (Zapatos en la Orilla del Danubio, Can Togay y Gyula Pauer, 2005) consta de unos sesenta pares de zapatos de hierro que están colocados de manera aleatoria en la ribera oriental del río a su paso por la capital húngara. El monumento es el más popular de la ciudad, tanto que ha dejado en el olvido a los que ya se habían dedicado con anterioridad a denunciar hechos de violencia extrema que habían practicado los húngaros aliados de los nazis. Esto sucede mientras Hungría se encuentra inmersa en un régimen que mantiene una relación con el pasado traumático que incide en la negación del rol colaboracionista del país en el exterminio nazi (Kovács \& Mindler-Steiner, 20I6: 54). No siempre había sido así. Ya en I945, una calle fue bautizada con el nombre de Raoul Wallenberg, primer secretario de la embajada sueca en Budapest y personalmente responsable de salvar la vida de 
miles de judíos, en la antigua zona del gueto. También se había colocado una placa dedicada a su memoria en uno de los muros del gueto internacional. En I949, se había erigido un "memorial por los mártires" en el Cementerio Central Judío en Pestlôrinc (el cementerio judío más grande del país). Para ser más exactos, ya existía en Budapest un memorial dedicado a la cuestión de los fusilamientos en el Danubio, por cierto localizado más cerca del sitio donde la violencia había tenido lugar. Se trata de una serie de azulejos colocados en el suelo (Llorando hacia el cielo, Anna Stein, I990) que dicen: "En memoria de los Húngaros que fueron víctimas del terror de la Cruz Flechada en invierno de I944-I945”. (Munteán, 2020). Por lo tanto, el monumento de los zapatos estaba muy lejos de desvelar una verdad incómoda u oculta que precisaba salir a la luz. Simplemente, era un memorial que venía a construirse en una ciudad que ya tenía memoriales existentes, algunos dedicados exactamente a los mismos hechos.

\section{El culto a las víctimas y la ausencia de los verdugos}

El caso de Hungría no es una excepción en una época en que la consagración de la memoria parece ir de la mano del olvido. En este sentido, la disolución de la identidad de víctimas y verdugos adquiere un nuevo significado en el marco de la política europea de equiparación de todos los "totalitarismos". Esto fue consagrado por el Parlamento Europeo en 2009 con la declaración del día 23 de agosto (Pacto Ribbentrop-Molotov) como "Día europeo conmemorativo de las víctimas de todos los regímenes totalitarios y autoritarios", con una equiparación políticamente motivada de las víctimas del nazismo y el estalinismo. En noviembre de 2006, el presidente ucraniano Viktor Yushchenko firmó la llamada "Ley del Holodomor de i932-I933", que el Verkhovna Rada (Parlamento Ucraniano) adoptó en Ucrania. Al calor de esta medida, se inauguró en 2008 un enorme memorial en Kiev con motivo del $75 .^{\circ}$ aniversario de la hambruna que azotó a los ucranianos por causa de las políticas soviéticas (Anatoliy Haydamaka \& Yuriy Kovalyov, 2008). El elemento visible del memorial es una estatua llamada "El amargo recuerdo de la infancia", que representa la figura de una niña que tiene entre las manos una espiga de trigo. Los tableros adyacentes tienen un listado de los 14.000 pueblos y ciudades de Ucrania víctimas del hambre y de los confinamientos decretados por las autoridades estalinistas para evitar que la población huyese (Belleza, 20I5: 243-246). Por supuesto, no hay ninguna mención (ni se pretende hacerla) al 
papel que los propios ucranianos pudieron tener en la implementación de estas políticas, en las que colaboraban con los designios estalinistas. Como tampoco existe un monumento semejante a su papel colaboracionista con los ocupantes nazis.

En los países del centro y el este de Europa proliferan los monumentos y memoriales dedicados a hacer recordar los "crímenes del comunismo", también al tiempo que determinados gobiernos de signo autoritario crecen con unos discursos fuertemente anclados en el rechazo a la memoria del antifascismo, que había sido el corazón de la memoria europea. Estas políticas de la memoria cuyos orígenes se pueden rastrear en la Europa posterior a I989, son institucionalizadas en la década de 20ı. Como representa el ya mencionado caso húngaro, los actuales gestores políticos del país no se reconocen en el papel de perpetradores, de colaboradores activos del exterminio nazi. Solo se reconocen en la condición de víctimas (Benazzo, 20I7: 2I3-2I4). La proliferación de memorias, de víctimas, y las políticas de recuerdo no son un juego de suma cero. Añadir nuevos recuerdos a otros existentes crea importantes disrupciones en lo que constituye el patrimonio común de la memoria colectiva. La cultura de la memoria por más que ofrece una proliferación de monumentos, placas y homenajes a las diversas víctimas, no parece poseer la capacidad taumatúrgica de "curar el pasado". En los cada vez más frecuentes espacios memoriales, se percibe la cada vez más evidente ausencia de los verdugos. Tal y como ha sucedido en los espacios memoriales del "holocausto" (Mauthausen, I998), se cuestiona también la exposición de determinadas imágenes de víctimas que puedan "repetir simbólicamente el accionar de los verdugos" (Dürr, 2018: 26). Un razonamiento de ese tipo aplicado a un campo de exterminio del nazismo solo tiene sentido en la época de memoria que vivimos, pues la representación de brutalidad de los verdugos en aras de su denuncia (así como la exaltación de la resistencia de sus víctimas) era incuestionable con la lógica en que se intervinieron aquellos espacios inicialmente (Míguez, 2020: 8I-86).

Las demandas de memoria parecían ser inacabables y esto sucedía y sucede a nivel global. Así, en América de norte a sur, podemos ver los monumentos dedicados al recuerdo de elementos del pasado traumático. Este es el caso del proyecto de conmemoración del "Sendero de Lágrimas", llevado a cabo por el National Park Service en Estados Unidos desde al año 2000, que incluye la señalización del camino de deportación forzosa que llevó entre i838 y I839 a los Cherokee desde sus hogares en Tennessee, Alabama y Carolina del Norte hasta su "relocalización" en Oklahoma (National Park Service, 2020). 
También son los casos del Museo del Holocausto de Washington (I993) y del Museo Nacional del legado Afroamericano también en la capital federal de Estados Unidos (20I6) (Burns, 20I3). El contraste entre ambos museos es significativo por diversos motivos. Ambos definen bien los límites del papel de la denuncia en la nueva era de la memoria, ya que aunque el museo del Holocausto asume la narrativa plena del combate del negacionismo, el planteamiento mucho más consensual del museo de legado afroamericano se percibe en el relegamiento relativo del papel de la "esclavitud" en su definición. Desde luego, el museo del legado afroamericano resulta mucho menos contundente a la hora de señalar "verdugos" que en el caso del dedicado al Holocausto o en el llamativo memorial también erigido en Washington dedicado a recordar la memoria del Holodomor (Larysa Kurylas, 20I5).

En el Cono Sur americano se desarrolló otro gran foco de producción memorial, particularmente alrededor de los casos de Argentina y Chile. Existen desarrollos monumentales especialmente significativos, como es el Parque de la Memoria situado en la ciudad de Buenos Aires. El monumento se construyó después de ser aprobada por la legislatura de la ciudad en I998 la cesión de una franja de la costanera del Río de la Plata para emplazar un "monumento y grupo poliescultural en homenaje a los detenidos-desaparecidos y asesinados por el terrorismo de Estado durante los años 70 e inicios de los 80" (Boletín Oficial de la Ciudad de Buenos Aires, I998). Se trataba de la primera ocasión en que un monumento de estas características se aprobaba en Argentina con un amparo institucional de tal nivel. Desde ese momento y hasta su inauguración en 2007 , surgieron toda una serie de disputas, entre ellas, la cuestión crucial de quién se incluía en la categoría de víctima (Vezzetti, 2009: 2I4-2I5). El centro del espacio memorial está ocupado de hecho por un enorme muro donde están inscritos los nombres de las víctimas, remedando el memorial de Vietnam (Maya Lin, I982). Esta monumentalización del pasado traumático eludió totalmente la cuestión de los verdugos, en el momento de concepción del parque protegidos por las leyes de impunidad e indultos vigentes. No fueron los monumentos los que se ocuparon del asunto, sino la acción de la justicia (como ya había sucedido en I984-I985) a partir de la reversión de todas las medidas de impunidad, de 2003 en adelante (Míguez, 20I4: 2I6-2I7). En la propia forma de abordar la representación de los perpetradores allí donde se ha tenido el valor de enfrentarla, como en el caso notorio de Parque por la Paz Villa Grimaldi en Chile, se percibe una cierta traslación de la lógica jurídico-penal. Una de las principales representaciones concretas de los perpetradores en el espacio memorial es un organigrama de la DINA en las que se 
decidió incluir "únicamente, a aquellos agentes que habían sido condenados penalmente" (Rebolledo \& Sagredo, 2020: 222).

Algo semejante sucede con la memoria del genocidio en Camboya (I975 y I979). El régimen de los jemeres rojos fue el responsable directo del asesinato de un millón y medio de personas (Kiernan, 2002). El memorial de Choeung Ek (I988) está construido en el lugar de uno de los principales campos de exterminio del régimen de Pol Pot. Adopta la forma de una Stupa budista que contiene alrededor de cinco mil cráneos. En el caso del genocidio en Camboya la inmensidad y transversalidad del volumen de víctimas, un porcentaje que oscilaba entre el 15 y $20 \%$ de la población, evidencia la imposibilidad de negar la existencia de la masacre. No hay nada que desvelar con el monumento que referimos que no fuera bien conocido, mucho más cuando habían pasado menos de diez años de la caída del régimen. Tanto Pol Pot como algunos de sus colaboradores aún estaban vivos y refugiados en algún lugar de la selva, siguiendo un combate guerrillero que para finales de la década de iو80 no tenía posibilidades reales de triunfo (Sion, 20II: 6-8). En todo caso, el propósito del memorial se refería exclusivamente a un principio que se convierte en piedra angular de la era de la memoria: lo que se pretende combatir es el olvido. Todo ello explotado en el marco de su potencial turístico. De hecho, Camboya se representa como un espacio privilegiado del llamado dark tourism (Beech, 2009: 223). Tampoco fueron aquí los monumentos los que se ocuparon de la cuestión de los verdugos, sino la acción de la justicia con el funcionamiento de un tribunal internacional auspiciado por la ONU. Y en este proceso, la limitación de la acusación a un grupo muy selecto de responsables, plantea también la escasa consideración a la participación social en la violencia.

\section{A modo de conclusión: el perpetrador sigue encerrado en su laberinto}

La idea motriz del nuevo ciclo de memoria es que los acontecimientos vengan a ser rememorados continuadamente, fundamentalmente con fines políticos del presente. Observamos cómo los elementos disruptivos de la memoria que estaban vigentes en la actividad de memorialización de los pasados traumáticos hasta la década de I990 van progresivamente acomodándose a los nuevos estándares, definitivamente globalizados y homogeneizados. Se trata de recordar a las víctimas, con un propósito que se explica en sí mismo. Pero, ¿son de hecho todas las víctimas iguales? Históricamente no lo han sido. La 
propia sucesión de los regímenes de memoria lo demuestra, acompañados inexorablemente de la construcción de la noción de víctima. Las víctimas que los memoriales recuerdan incluyeron globalmente a los soldados del Séptimo de Caballería, la tribu del jefe Pie Grande masacrada en Wounded Knee, los caídos del bando blanco y los caídos del bando rojo en Finlandia, las víctimas del velódromo de París y los del Danubio a su paso por Budapest, los fusilados en el foso de Santa Elena y los miles de cuerpos mezclados en las criptas del Valle de los Caídos. Son precisamente los perpetradores y todas las actitudes intermedias ante la violencia las que nos permiten diferenciar a las víctimas y, justamente por ello, identificarlas.

En este sentido, el camino que hemos emprendido en los últimos treinta años en la globalización de la memoria va en sentido contrario. A partir de la instauración del régimen de memoria actual, el recuerdo constituye causa y efecto de las acciones de memoria. No importa que el suceso ya estuviera memorializado, si existe la posibilidad de volver a recordarlo con un monumento generalmente más grande, más original o más atractivo para una creciente industria turística que se mueve alrededor de estos referentes culturales. No importa si el suceso no estaba aún rememorado en el espacio público, porque existe la posibilidad de hacerlo y la justificación de que se recuerde está autoexplicada en el acto de recordar. Un galimatías de lógica que se resume en el axioma de post hoc ergo propter hoc: recordamos porque el acontecimiento sucedió antes y porque el recuerdo es consecuencia del suceso. Ahora bien, si aceptamos el reto de diferenciar a las víctimas porque miramos a los perpetradores, debemos también asumir que la categoría de perpetradores merece una diferenciación propia: no existe el verdugo por antonomasia. Incluso debemos asumir que se contienen en un mismo sujeto diferentes ángulos, los de víctima, verdugo e indiferente observador, encerrados todos en el mismo laberinto del pasado.

\section{Bibliografía}

Andersson, Rani-Henrik. 2008. The Lakota Ghost Dance of 1890 . Lincoln: University of Nebraska Press.

Beech, John. 2009. Genocide Tourism. En Sharpley, Richard \& Stone, Philip R. (eds.) The Darker Side of Travel: The Theory and Practice of Dark Tourism. Bristol: Channel View Publications, 2I9-22I.

Belleza, Simone A. 20I5. Building Memory. National Identities and Monuments in Post-Soviet Ukraine. En Brogi, Giovanna E.; Dyczok, Marta; Pachlovska, Oxa- 
na \& Siedina, Giovanna (eds.). Ukraine twenty years after independence. Assessments, perspectives, challenges. Roma: Aracne, 237-247.

Benazzo, Simone. 20I7. Not All the Past Needs To Be Used: Features of Fidesz's Politics of Memory. Journal of Nationalism, Memory a Language Politics II (2): I98-22I.

Boletín Oficial del Gobierno la Ciudad de Buenos Aires. I998. Ley 46. Paseo Público y monumento en memoria de las víctimas del terrorismo de Estado. BOCBA, 5I4, 25/08/1998.

Boletín Oficial del Estado. I940. Decreto de i de Abril de I940, disponiendo se alcen Basílica, Monasterio y Cuartel de Juventudes, en la finca situada en las vertientes de la Sierra de Guadarrama (El Escorial), conocida por Cuelgamuros, para perpetuar la memoria de los caídos de nuestra gloriosa Cruzada. BOE, 93, 2/04/I940, 2240.

Boletín Oficial del Estado. 2007. Ley 52/2007, de 26 de diciembre, por la que se reconocen y amplían derechos y se establecen medidas en favor de quienes padecieron persecución o violencia durante la guerra civil y la dictadura. BOE, 3I0, 27/I2/2007, 534IO-534II.

Boletín Oficial del Estado. 20ı8. Real Decreto-ley ıо/20ı8, de 24 de agosto, por el que se modifica la Ley 52/2007, de 26 de diciembre, por la que se reconocen y amplían derechos y se establecen medidas en favor de quienes padecieron persecución o violencia durante la Guerra Civil y la Dictadura. BOE, 206, 25/08/2018, 84607-846io.

Burns, Andrea A. 2013. From Storefront to Monument: Tracing the Public History of the Black Museum Movement. Amherst: University of Massachusetts Press.

Dürr, Christian. 20I9. Acusación y terapia: los Gedenkstätten en Alemania y Austria y los sitios de memoria en Argentina. Kamchatka. Revista de Análisis Cultural I3: $13-29$.

Centro de Investigaciones Sociológicas. 2005. Estudio CIS $n^{0}$ 2622. Barómetro de octubre de 2005. Madrid: Centro de Investigaciones Sociológicas. http://www. cis.es/cis/opencm/ES/I_encuestas/estudios/ver.jsp?estudio=4977 [Acceso: 28/05/202I]

Fabre, Jaume; Huertas Josep M. \& Ainaud, Joan Francesc. 20I6. A los Caídos del Foso de Santa Elena. http://wio.bcn.cat/APPS/gmocataleg_monum/FitxaMonumentAc.do?idioma=ES\&codiMonumIntern $=464$

Ferrándiz, Francisco. 20I4. El pasado bajo tierra. Exhumaciones contemporáneas de la Guerra Civil. Barcelona: Anthropos.

Grua, David W. 2015. "In Memory of the Chief Big Foot Massacre". The Wounded Knee Survivors and the Politics of Memory. Western Historical Quarterly 46: 3I-5I.

Halbwachs, Maurice. 2004. Los marcos sociales de la memoria. Barcelona: Anthropos. Heimo, Anne \& Peltonen, Ulla-Maija. 2003. Memories and histories, public and private: After the Finnish Civil War. En Katharine Hodgkin \& Susannah Radstone (eds.) Contested pasts: The politics of memory. Londres: Routledge, 42-56. 
Kiernan, Ben. 2002. The Pol Pot Regime: Race, Power and Genocide in Cambodia under the Khmer Rouge, 1975-1979. New Haven: Yale University Press.

Kovács, Henriett \& Mindler-Steiner, Ursula K. 20I6. Hungary and the Distortion of Holocaust History: the Hungarian Holocaust Memorial year 20I4. Politics in Central Europe. Central European Political Science Association II (2): 49-72.

Koselleck, Reinhart. I993. Futuro Pasado. Barcelona: Paidós.

Laqueur, Thomas W. I996. Memory and Naming in the Great War. En Gillis, John R. (ed.) Conmemorations: the politics of national identity. New Jersey: Princeton University Press, I50-I67.

Míguez Macho, Antonio. 2014. La genealogía genocida del franquismo. Violencia, memoria e impunidad. Madrid: Abada.

Míguez Macho, Antonio. 2020. Justificación, denuncia y olvido. Una interpretación histórica de los regímenes de memoria de nuestro tiempo. En Cañón, Lisandro \& Román, César Manuel (eds.). Estado de excepción y terrorismo de Estado. Córdoba: Lago, 67-IIo.

Mosse, George L. I990. Fallen Soldiers. Reshaping the Memory of the World Wars. Nueva York: Oxford University Press.

Munteán, László. 2020. Shockwave Memories: Multidirectional Sites of the Holocaust in Budapest. En Kalogeras, Yiorgos \& Waegner, Cathy C. (eds.) Ethnic Resonances in Performance, Literature, and Identity. Londres: Routledge, 64-83.

Musée de la Résistance. 20I3. Square de la Place-des-Martyrs-juifs-du-Vélodrome-d'Hiver. http://museedelaresistanceenligne.org/media5394-Square-de-la-Place-desMartyrs-juifs-du-VA [Acceso: 28/05/202I]

National Park Service. 2020. Trail of Tears. https://www.nps.gov/trte/index.htm [Acceso: $28 / 05 / 2020]$

Olick, Jeffrey K. 2007. The politics of regrets. On Collective Memory and Historical Responsibility. Londres: Routledge

Peltonen, Ulla-Maija. 2002. Civil war victims and the ways of mourning in Finland in I9I8. En Christie, Kenneth \& Cribb, Robert (eds.) Historical injustice and democratic transition in Eastern Asia and Northern Europe. Ghosts at the table of democracy. Londres: Routledge, I84-I97.

Rebolledo Hernández, Daniel \& Sagredo Mazuela, Omar. 2020. ¿Cómo representar a los represores en un sitio de memoria? El caso del Parque por la Paz Villa Grimaldi. Atenea 52I (I): 2II-229.

Sion, Brigitte. 20II. Conflicting Sites of Memory in Post-Genocide Cambodia. Humanity: An International Journal of Human Rights, Humanitarianism, and Development 2(I): I-2I.

Suomen Sotasurmat. [I9I4-I922]. 2004. War Victims in Finland. http://vesta.narc.fi/ cgi-bin/db2www/sotasurmaetusivu/stat2 [Acceso 28/05/202I]

Szpunar, Piotr M. 20I2. Collective Memory and the Stranger: Remembering and Forgetting the I9I8 Finnish Civil War. International Journal of Communication 6: I2OO-I22I. 
Tikka, Marko. 20I4. Warfare and Terror in I9I8. En Tepora, Tuomas \& Roselius, Aapo (eds.) The Finnish Civil War 1918. History, Memory, Legacy. Leiden: Brill, 90-II8.

Upton, Anthony F. 1981. The Finnish Revolution. Mineápolis: University of Minnesota Press.

U. S. Army Garrisons. 2020. Historic Fort Riley. https://home.army.mil/riley/application/files/9915/04I2/1300/HistoricAttractions.pdf, [Acceso 28/05/202I]

Utley, Robert M. 2004. The Last Days of the Sioux Nation. New Haven: Yale University Press.

Vezzetti, Hugo. 2009. Sobre la violencia revolucionaria. Memorias y olvidos. Buenos Aires: Siglo XXI.

Wieviorka, Annette. 1999. Le Vel' d'Hiv': histoire d'une commémoration. En Coq, Christian \& Bacot, Jean-Pierre (eds.) Travail de mémoire 1914-1998 - une nécessité dans un siècle de violence. París: Editions Autrement. 